\title{
The Performance of Undershot Water Wheel On Irrigation with Four Steps Mechanical Transmission and A Flywheel
}

\author{
Asral $^{\# 1}$, Warman Fatra ${ }^{* 2}$, Indra Yasri ${ }^{\# 3}$ \\ \#1,2 Department of Mechanical Engineering, Universitas Riau, Pekanbaru, Riau 28293, Indonesia \\ ${ }^{\# 3}$ Department of Electrical Engineering, Universitas Riau, Pekanbaru, Riau 28293, Indonesia \\ ${ }^{1}$ asral@lecturer.unri.ac.id \\ ${ }^{2}$ warman.fatra@eng.unri.ac.id \\ 3 indra.yasri@lecturer.unri.ac.id
}

\begin{abstract}
This study is about the used of a flywheel in an effort to improve the performance of waterwheel on irrigation channels. Flow in irrigation has low head differences including low coupled lies in lowland areas. Waterwheel undershot-type appropriate for low high head applications in an attempt to gain the electricity. A set of waterwheel developed has an outer diameter of $\mathbf{2} \mathbf{m}$ with 12 pieces of curved-blade prepared from the material of aluminum. On the shaft of pully-belt of the step transmission conditioned the mass as flywheel varied $2-42 \mathrm{~kg}$ designed to performs concurrently with water wheel system. The height of flow water controlled by a sluice gate to find out the potential. As the results the performance of water wheel very dependent on the height of irrigation water. The mass of flywheel on the water wheel system can increase the rotation up to $215 \%$ as it produces the maximum electrical power of about $390 \mathrm{~W}$.
\end{abstract}

Keyword - Water wheel, Irrigation, River, Flywheel, Turbine

\section{INTRODUCTION}

Irrigation channels in the Koto Tibun Village are primarily provided for irrigating of agricultural land and for water supply of fisheries. This study is about the use of flywheel in order to improve the performance of undershot waterwheels. The flywheel is usually selected as a component for energy storage. A flywheel is useful for generating power to reduce the load on the generator when demand is instantly increasing, allowing the generator to maintain speed and frequency. The energy can be returned to the flywheel when the demand is reduced. Therefore, the flywheel is usually situated and turned on the shaft together.

Many studies with using flywheel on the machine, but limited data for the water wheel such as a flywheel application on a multicrop threshing machine [1]. Based on their study found that $12 \%$ of the material cost and operational load on the shaft and bearings decreased and kinetic energy storage capacity increased. Another study, The Dual Mass Flywheel is used to damp the oscillations on the train engine in order to prevent shocks on the gearbox [2]. The comparative study shows that the Dual Mass Flywheel 5-6\% more efficient than conventional flywheels in its use. Then there is an increase in power of about $7-8 \%$.

In throughout the irrigation channels might provide a large amount of potential energy as well. According to that condition, the regulation and optimizing the use of water resources for consumption, irrigation and hydroelectric power plant should be considered, like study have been conducted by Wu and Chen [3]. Yet, relevant to that an essential study in order to improve the energy production by water power plant concern with applied the combination water cycle power generating system has been studied by Liu and Packey [4].

Again, many studies have been conducted in order to investigate alternative and renewable energy resources. A study presents a description of the initial testing performed on the prototype pico hydro generator system for the purpose of investigating the performance [5]. The kinetic energy contained in the flow of water in domestic pipes is known to have the potential to generate electricity for energy storage purposes while performing routine activities such as laundry, cooking, and bathing. The water pressure and water flow in the pipe from the main tank utility, which is used for the activities of everyday life, used for small-scale hydro turbines rotate to drive a generator for generating electricity. The test results indicate that the readings are significantly convincing in terms of electrical voltage recorded since it can be calculated to be followed is this system is feasible for electrification aimed at storage of energy and showed good prospects for improvement and further research in the future.

Furthermore, the development of a waterwheel has been carried out traditionally where it has fulfilled the needs of the water in an agricultural area [6]. In a region, wherein the water resources are available abundantly caused these efforts are highly recommended as a solution to energy deficiency in the rural area. Indonesia has the potential for hydropower are about 75.5 GW [7]. One of the sources of hydropower like that has available in Riau province where 250,571 hectares of land have been completed by the medium of irrigation canals. 
In order to find the new energy resources and utilization the irrigation flow where the energy is provided free of charge, the development of small-scale hydro turbine into a proper object to be investigated. The main objective of this study is to investigate the performance of undershot water wheel for electrical generation with the flywheel on mechanical transmission in accordance with the potential based on an irrigation at Koto Tibun village.

\section{METHODS}

This field study was carried out at an irrigation in the Koto Tibun Village of Indonesia Riau Province. The Koto Tibun village is about $40 \mathrm{~km}$ from Pekanbaru city located in the Kampar district area. The economic life of society generally is good enough. Their source of livelihood is mostly from farming and raising fish. For that reason, the local government sees about to equip with enough watering facilities. However, the provision of these facilities is not accompanied by the knowledge about the utilization of water resources as well by conducting the interviews known that most people did not know how to develop the water resources as an electricity generator. Lack of electricity supply means affecting the business community in the field of fisheries. The wheel drive motor and lighting in the growing period of the fish are significant to develop the production.

The irrigation of the test is a channel branched from a small dam as the flow predicted provides like sufficient energy as described in Fig. 1. In around of the irrigation found the houses and the people have the daily activity. This irrigation used for flowing the fish pond and other like bathing and washing. The spot of the water wheel testing is about $50 \mathrm{~m}$ from the dam downstream.

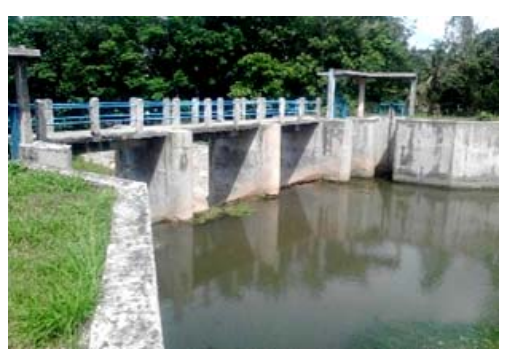

(a)

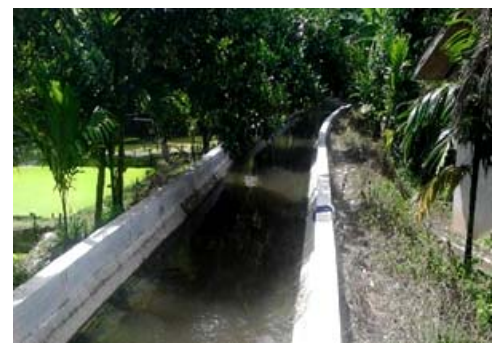

(b)

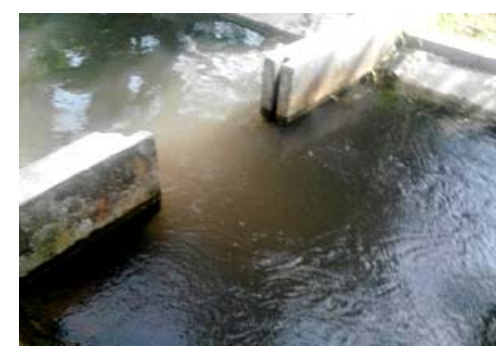

(c)

Fig. 1. The irrigation profile at Koto Tibun Village, (a) Small dam, (b) Irrigation channel, and (c) Spot testing

The data are collected from varying the height of water level which represents the flow rate. The level of water controlled by a sluice gate on the dam for every $2 \mathrm{~cm}$ of change. However, the water level come into the waterwheel is maintained between $60 \mathrm{~cm}$ to $90 \mathrm{~cm}$ in line to prevent disrupting the village activities. To determine the flow velocity, the time the drift ball is measured with a stopwatch at the specified distance. Since the irrigation wall like tilted, it can help determine the area of the channel easily. The flow rate is then determined as the amount of volume flow per time. This approach is done as a solution to the limitations of measuring instruments in field study and is an easy method to find the parameter of flow.

The state of the flow at the location is included in energy resources with low head, it can be seen regularly from the small flow rate. The main components of the system are a waterwheel, four-step pully-belt transmission system and an electric generator as shown in Fig. 2

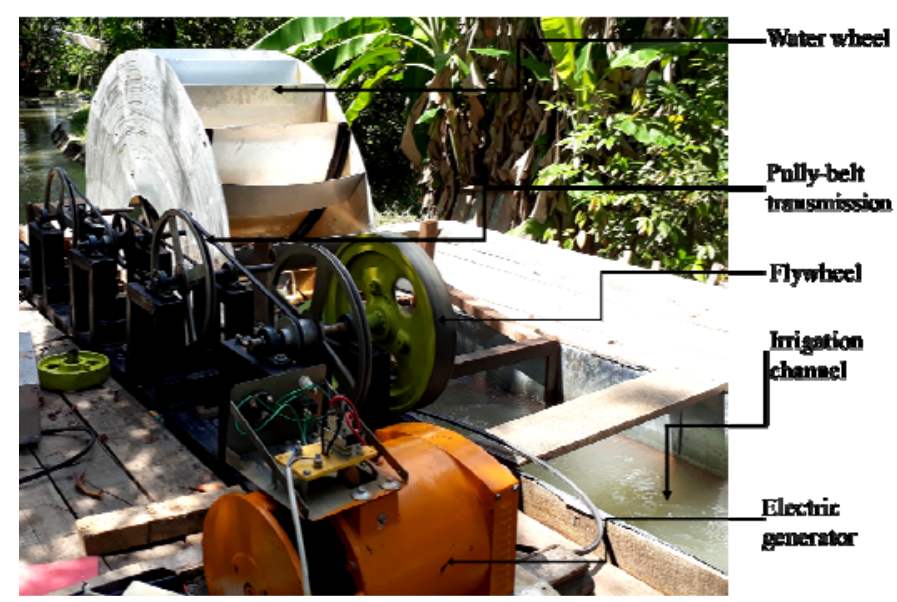

Fig. 2: The arrangement of the experimental apparatus, set up on irrigation 
Related to the experimental apparatus, the mass of flywheel varied and located on respectively, for four steps of shafts pully-belt transmission system. The definition of steps has shown in Fig. 3. The mechanical power transmission system with multi-step is intended to obtain the appropriate rotation for a hydropower with a pulley diameter ratio. In accordance with the characteristics of the flow with low head, the waterwheel with one step transmission prediction has produced lower rotation.

The effect of the flywheel mass on the results is carried out as the optimum water level obtained. The variations of the mass of $2 \mathrm{~kg}-42 \mathrm{~kg}$ is investigated respectively on rotation and electric voltage output. In throughout of this study the influence of the flywheel radius has not been considered. The work as illustrated in Fig. 4.

In order to find out the optimal height of the water level, in this study, the height of the water is adjusted from the maximum height water that could be accommodated in the channel until the water level could no longer work the waterwheel. Meanwhile, the height is a representation as flow in the irrigation where the height difference (head) is rather constant. Then, on every shaft of the four-step transmission and an electric generator have measured the rotation. Electrical voltage has measured at the output terminal on the generator.

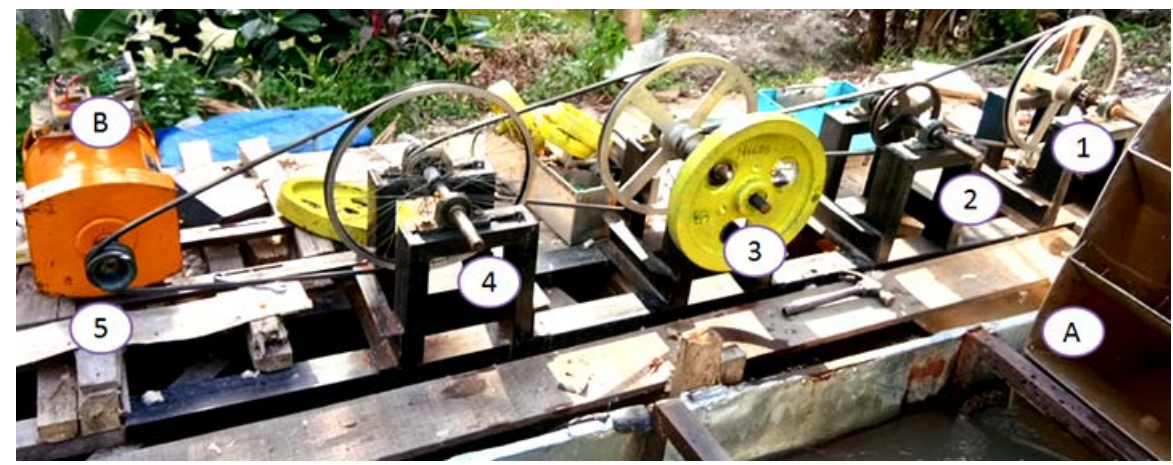

A. Waterwheel

B. Electric generator

1. Shaft $s$ tep-1

2. Shaft step-2

3. Shaft step-3

4. Shaft step-4

5. Shaft 5 (Generator)

Fig. 3: Pully and belt for four-steps of mechanical power transmission with the flywheel
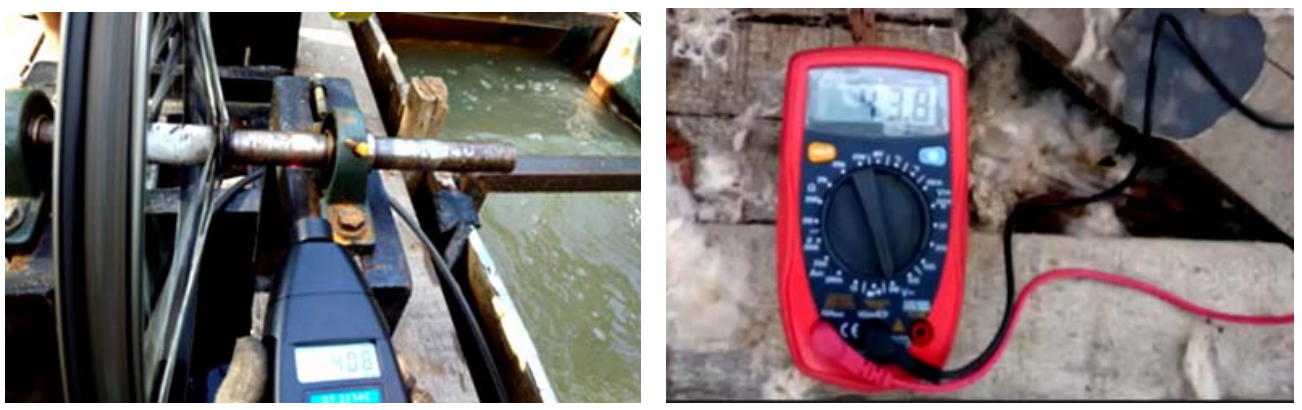

Fig. 4: The measurement of voltage and shaft rotation

To find out the flow rate, the measurement has done to the flow on the surface for the various heights of water. Furthermore, the relationship between the flow rate and water height variations determined, as can be seen in Fig. 5. From the graph shown that the water height and the flow rate are increasing as linear. So from this result, then stated that the change in water height is equivalent to the change of flow rate. The characteristic of both components look like the agreement.

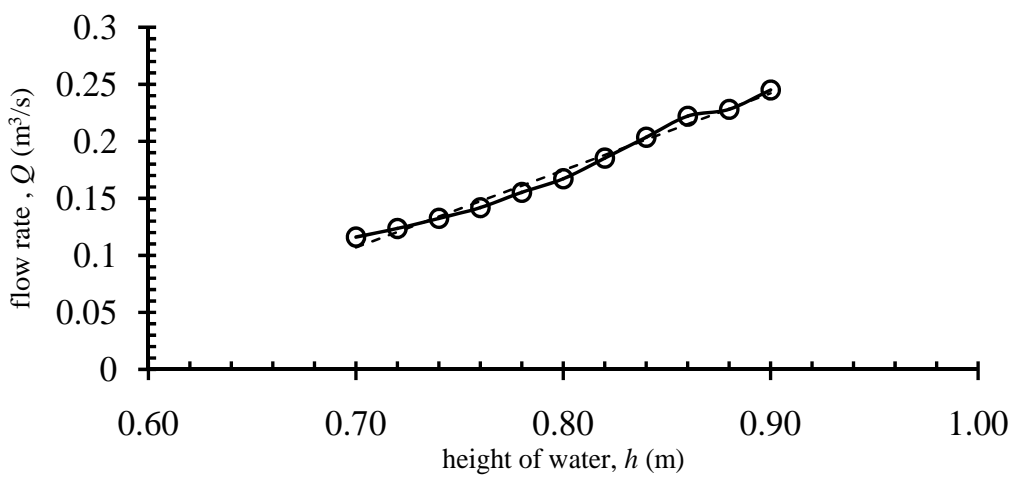

Fig. 5: The relationship between the water height and the flow rate 


\section{RESULTS AND DISCUSSION}

The results of waterwheel with no flywheel on the mechanical transmission system with the various heights of water ratio are shown in Fig. 6. Clearly seen from the figure that as the height of water increases, then the rotation and the voltage are increased. The productivity of the waterwheel as pico-hydropower start to rise when the height of water ratio at the inlet is about 0.8. Meanwhile, the rotation and voltage show proportional, then the increase in rotation causes an increase in the voltage as the electrical generator output. This data implies that an increase in the amount of the energy converted by the mill as the flow rate increases. This fact is a logical consequence on a generating system and has become a reference by many relevant studies. Stationer condition occurs as the height of water ratio in the range of 0.7-0.8. It might be due to insufficient force flow to push the blades of waterwheel as generating system. The machine starts to turn as the flow is greater than the total number of inertia force. The achievement like that occurs as the height of the water is about 0.78 .
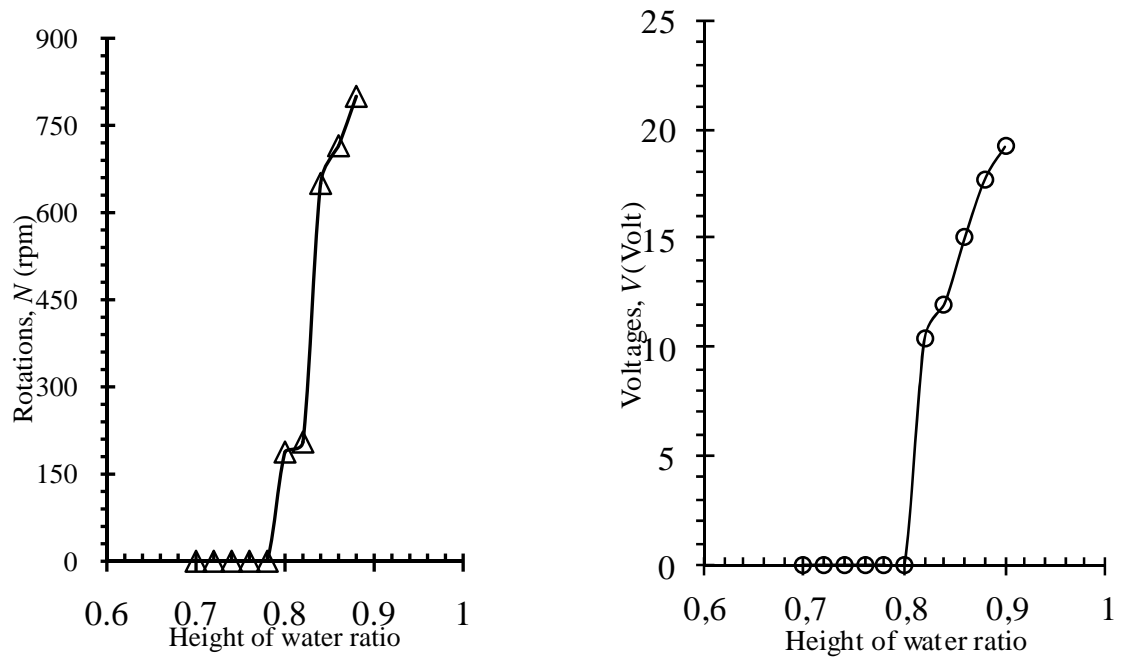

Fig. 6: Characteristics effect of water height changed on rotation

Fig. 7 show the effect of the mass of flywheel on the rotation as the position on the shaft-step of change. The mass flywheel under these circumstances is constant. Clearly shown from the figure that as the position completely changed on the step lead to increment on the rotation of shaft generator. Minimum achievement seems to in the transmission condition with no flywheel. The evidence shows that the flywheel has provided the energy when the system experience deficient, but it has to save if more energy. Optimal performance for flywheel positioned has on the 4th-step shaft. The difference reached $220 \mathrm{rpm}$, about $25 \%$ increment from the conditions with no mass of flywheel. This result shows the fact that all these conditions suitable for multi-step transmission system application.

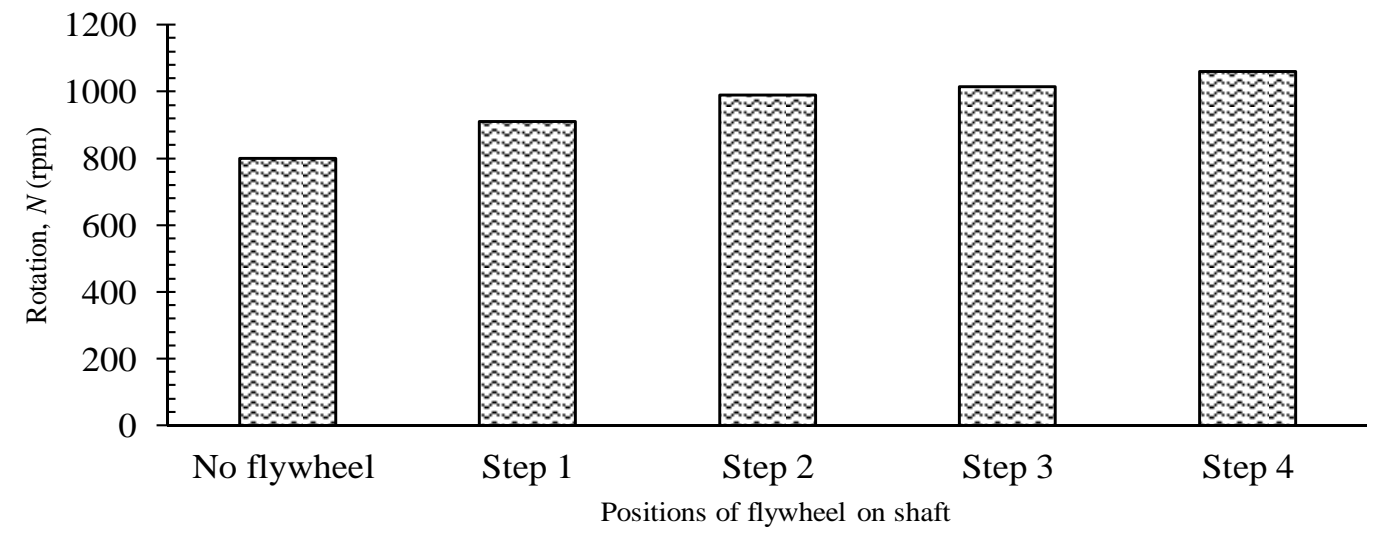

Fig. 7: Various flywheel position effect on the rotation 
Fig. 8 shows the variations effect of the flywheel position on each shaft-step for rotation as the load remains constant. In accordance with the design purposes of the multi-step transmission system that to obtain a higher rotation at the last step has been proven based on these data. The fact that the addition of a flywheel on the respective shift can increase the rotation has clearly visible from the figure. The rotation increases significantly based on the order of each up to the 4th-step shaft reach $233 \%, 146 \%, 145 \%$, and $215 \%$. These results demonstrate good achievement in an attempt to stabilize and improve the rotation as a whole flywheel condition could provide like energy when the system requires.

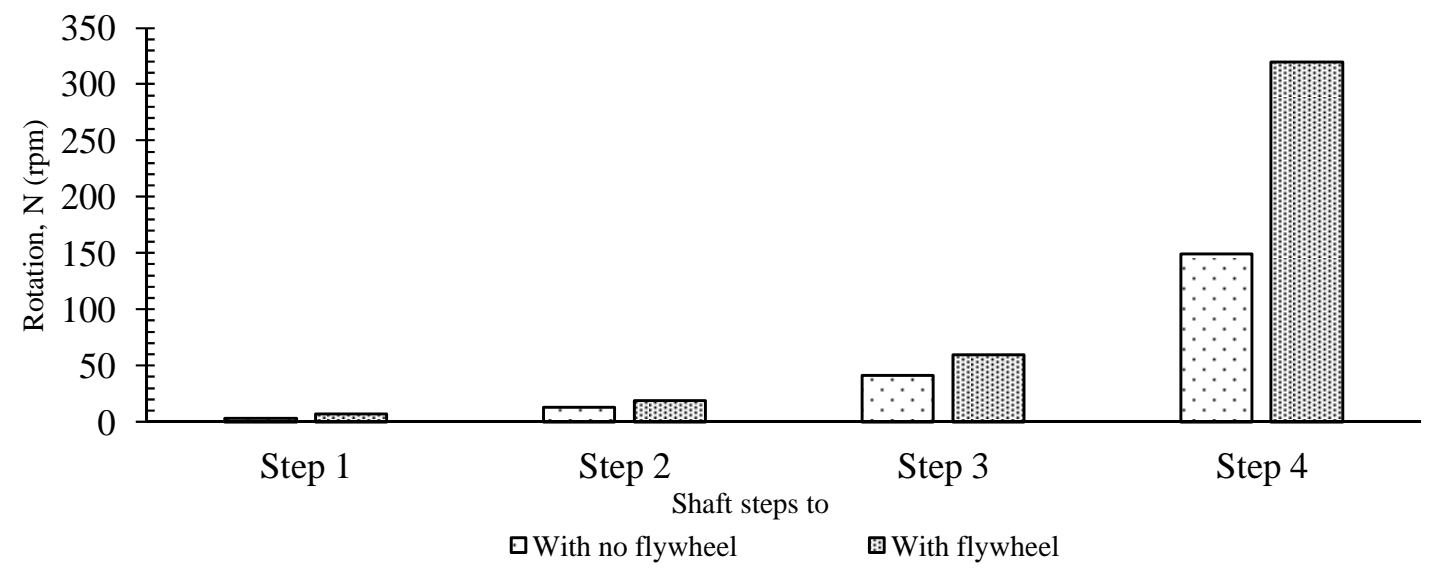

Fig. 8: The effect of the flywheel to shaft rotation

The change in the amount of flywheel mass on the shaft gives effect to the rotation of the power plant, as shown in Fig. 9. The achievement began from the first step flywheel position up to the $4^{\text {th }}$ step its increases reaches about $25 \%$. Besides that, the change of the flywheel position on the shaft it is necessary to be considered in order to improve the rotation. Despite the slow rise, but the addition of the flywheel mass has contributed to the stability and rise of the rotation. Because the flywheel provides an appropriate inertia force for the entire generating system. An increase in the mass of flywheel causes an increase in the rotation of the electrical generator. The change of the flywheel position appears to produce the highest rotation on step-4.

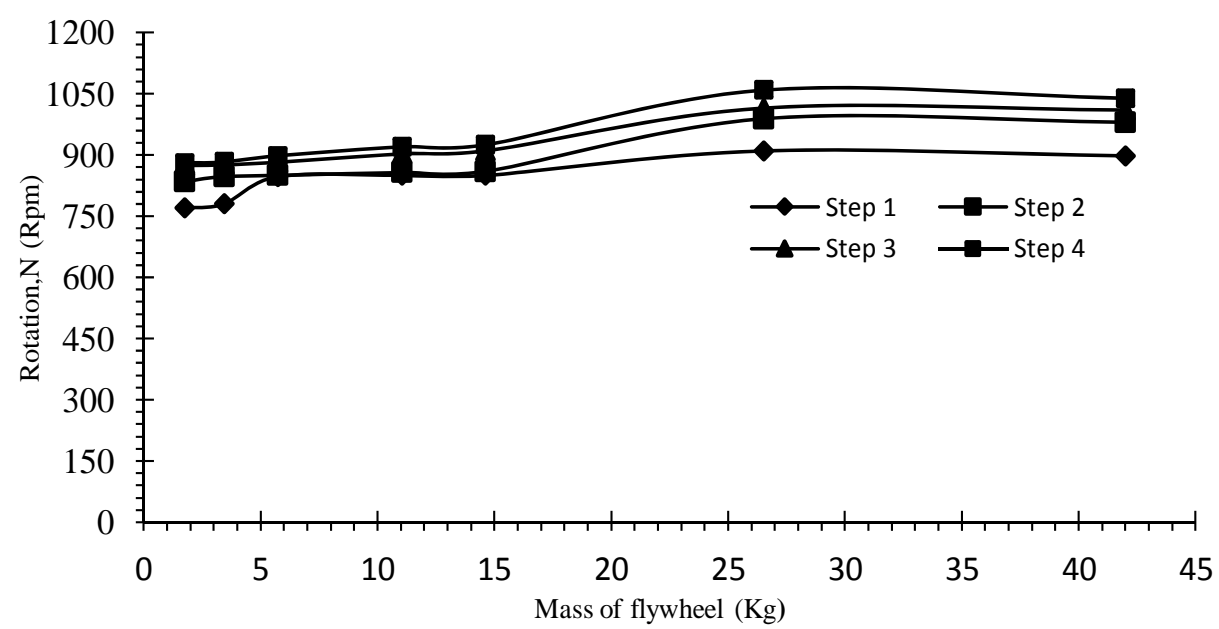

Fig. 9: Effect of mass flywheel variations on shaft rotation of the electrical generator

Fig. 10 shows the change in the mass of flywheel causes a significant effect on the generator output voltage. It is clearly seen that the electrical voltage increases reach up to $250 \%$ of the flywheel position on the 1 st-step to the 4-step. These results are achieved when the flywheel mass increased up to 10 times greater. The facts show that in its operation this generator system appears to require some energy supplement to increase its output power. The energy supplement is administered through the process at the time of the excess it saved, but at a time of shortage, it added. The fact on these results have agreed with the function and the flywheel works. 


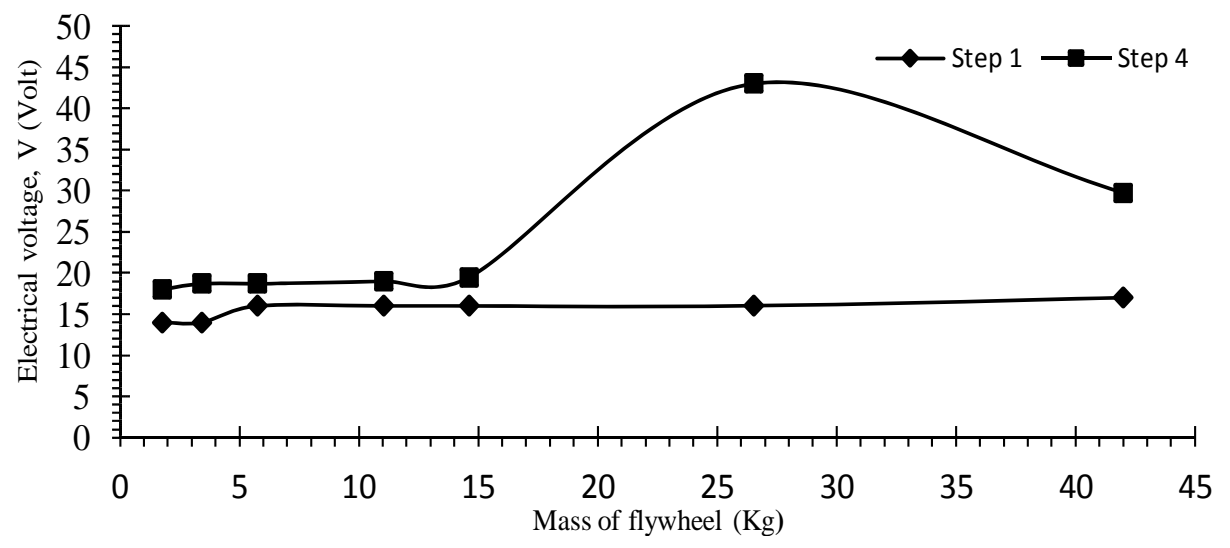

Fig. 10: Effect of mass flywheel variations on the electrical voltage of generator output

\section{CONCLUSION}

This study reveals the performance of undershot water wheel applied, particularly on rural irrigation with low head condition. The conclusion can be drawn are:

1. Multi-steps transmission system with flywheel can help improve the rotation achievement of the system.

2. The placement of the flywheel on the transmission is preferable on the $4^{\text {th }}$-shaft step or the step that is directly connected to the shaft of the electric generator.

3. The flywheel on the mechanical transmission system can increase the rotation up to $215 \%$.

4. The maximum power produced as water wheel system with no flywheel is about $170 \mathrm{Watt}$, but with the flywheel is about 390 Watt.

5. The performance hydropower very dependent on the height of water at the time of performing.

\section{ACKNOWLEDGMENT}

The authors would like to convey deep gratitude to Lembaga Penelitian dan Pengabdian Kepada Masyarakat Universitas Riau (LPPM-UNRI) which has provided financial support for completion of this research.

\section{REFERENCES}

[1] Samshette, Sagar M. and Swami, Mahesh C.,"Design Optimization and Experiments On Flywheel Using Thresher Machine, "International Journal of Research in Engineering and Technology Volume: 04 Issue: 10. 2015.

[2] Suryawanshi, N. N., Bhaskar, D. P., and Kopargaon, S.R.E.S,” An Experimental Study of Dual Mass Flywheel on Conventional Flywheel on Two Stroke Petrol Engine,” International Journal of Engineering Research and General Science, Volume 3, Issue 2, Part 2. 2015.

[3] Wu, Yiping, and Chen, Ji," Estimating irrigation water demand using an improved method and optimizing reservoir operation for water supply and hydropower generation: A case study of the Xinfengjiang reservoir in southern China,” Agriculture Water Management, Int. Journal, 116, 110-121. 2013.

[4] Liu, Yue, and Packey, Daniel J., "Combined-Cycle Hydropower Systems - The Potential of Applying Hydrokinetic Turbines in The Tailwaters of Existing Conventional Hydropower Stations,” Renewable Energy, Int. Journal, 66, 228-231. 2014.

[5] Ridzuan, M.J.M., Hafis,S.M., Azduwin, K., Firdaus ,K.M., and Zarina, Z.,” Development of Pico-hydro Turbine for Domestic Use,”Applied Mechanics and Materials, Vol. 695, pp 408-412. 2014.

[6] G. Akhyar Ibrahim, C. H. Che Haron and C. Husna Azhari, “Traditional Water Wheels as a Renewable Rural Energy,” The Online Journal on Power and Energy Engineering. 2014.

[7] BPPT, Outlook Energy Indonesia, Energy Ministry of Human Resources Republic of Indonesia. 2012.

[8] Tarjuelo, José M., Rodriguez-Diaz, Juan A., Abadía, Ricardo, Camacho, Emilio, Rocamora, Carmen and Moreno, Miguel A ,” Efficient Water and Energy Use in Irrigation Modernization: Lessons from Spanish Case Studies,” Agriculture Water Management, Int. Journal, 162, 67-77. 2015.

[9] Li , Yanrong, Nishi ,Yasuyuki, Inagaki, Terumi and Hatano, Kentarou, ” Study on the Flow Field of an Undershot Cross-flow Water Turbine,” Applied Mechanics and Materials Vol. 620, pp 285-291. 2014.

[10] Keawsuntia, Yuttachai, "Design and Test of Pico Crossflow Turbine for the Generation of Electricity for Use in the Rural Area," Applied Mechanics and Materials, Vols. 496-500, pp 605-608. 2014.

[11] Zhang, Lizhen, Cao, Xiaolong, Li, Juntao, and Wu, Shulei,” Design of New Small Hydroelectric Device,” Advanced Materials, Vols. 472-475, pp 883-886. 2012.

[12] Adhau, S.P., Moharil, R.M. and Adhau, P.G., "Mini-Hydro Power Generation on Existing Irrigation Projects: Case Study of Indian Sites”, Renewable and Sustainable Energy Reviews, Int Journal, 16, 4785-4795.2012. 


\section{AUTHOR PROFILE}

Asral is a lecturer in the Department of Mechanical Engineering, Universitas Riau since 1998. Doctorate studies were completed at the Department of Thermo Fluids, Universiti Teknologi Malaysia, in 2015. Some of the courses that have been taught are: Engineering Thermodynamics, Fluid Machinaries, Heat Transfer, and Engineering Mathematics. Research of interest: Flow structures, Lubrication, Water turbines and Computational Fluid Dynamics (CFD) Analysis.

Warman Fatra is a lecturer in the Department of Mechanical Engineering, Universitas Riau since 1999. The undergraduate study was completed at Mechanical Engineering Department of Universitas Andalas, Padang, in 1998, then Masters studies were completed at Institut Teknologi Bandung, Bandung in 2008. Courses that have been cared for are: Introduction to Engineering, Engineering Materials, Materials and Process Selection, Corrosion and Control Methods. Research of interest: Composites, Renewable Energy from palm waste oil.

Indra Yasri is a lecturer in the Department of Electrical Engineering, Universitas Riau. Continuing his Masters studies at Institut Teknologi Bandung, completed in 2007, then completing Doctorate studies at Universiti Teknologi PETRONAS, Malaysia in 2012. Some of the subjects that have been cared for include: image and video coding, engineering mathematics, and analog electronics. Research of interests are Wireless Sensor Network, Embedded System, and Video Image Processing. 